NyS 29

NYDANSKE STUDIER ชூ ALMEN KOMMUNIKATIONSTEORI 


\section{NyS 29}

(C) Artiklernes forfattere

Redaktion: Peter Juel Henrichsen, Anne Holmen, Marianne Johansen,

Bettina Perregaard, Jann Scheuer, Iben Stampe Sletten og Ib Ulbæk

Redaktionspanel: John E. Andersen, Frans Gregersen og Lars Heltoft

Oplysninger om abonnement og indsendelse af bidrag findes bagest i nummeret.

Institut for Dansk Dialektforskning, Københavns Universitet,

Njalsgade 80, 2300 København S

e-mail: jann.scheuer@hum.ku.dk

Internet: http://www.nys.dk/

Typografi og grafisk tilrettelægning: Kitte Fennestad MDD

Produktion: Clemenstrykkeriet A/S

Printed in Denmark 2002

ISBN 87-7704-835-0

Udgivet med støtte fra Statens Humanistiske Forskningsråd 


\section{N D H O L D}

FORORD 7

Pia Quist \& Jens Normann Jørgensen

INDFØDTE DANSKTALENDES VURDERING

AF UNGES ANDETSPROGSDANSKE TALESPROG 9

Christina Fogtmann

SUBJEKTET I HALLIDAYS FUNKTIONELLE GRAMMATIK 45

Martha Sif Karrebæk

DEN INDRE BLENDER 79

Anne Jensen

SÆTNINGSKNUDER I DANSK 105

Asgerd Gudiksen

NYE ORD 125 
